\title{
An inexpensive and accurate method of measuring the force of responses in reaction time research
}

\author{
Mats P. Englund and Geoffrey R. Patching \\ Stockholm University, Stockholm, Sweden
}

\begin{abstract}
Together with reaction time (RT), the force with which people respond to stimuli can provide important clues about cognitive and affective processes. We discuss some of the issues surrounding the accurate measurement and interpretation of response force, and present a response key by which response force can be measured regularly and unobtrusively in RT research. The advantage of the response key described is that it operates like a standard response key of the type used regularly in classic RT experiments. The construction of the response key is described in detail and its potential assessed by way of an experiment examining response force in a simple reaction task to visual stimuli of increasing brightness and size.
\end{abstract}

The force used to respond to stimuli is an additional dependent variable of considerable interest in interpretation of reaction time (RT) data (Angel, 1973; Carlton, Carlton, \& Newell, 1987; Schröter, 2006; Ulrich \& Wing, 1991). In studies of mental chronometry, RT is measured from the onset of the reaction signal to the depression of a sensitive response key and closure of an electric circuit. Yet, even with a simple keypress, there can be variation in the force of responses to stimuli (Ulrich \& Wing, 1991), termed response force. Response force is related physically to the speed of the response, ${ }^{1}$ but can continue beyond switch closure and so vary independently of RT (Carlton et al., 1987; Giray \& Ulrich, 1993; Haagh, Spijkers, van den Boogaart, \& van Boxtel, 1987; Ivry, 1986; Keele, Ivry, \& Pokorny, 1987; Schröter, 2006; Sommer, Leuthold, \& Ulrich, 1994; van Boxtel, van den Boogaart, \& Brunia, 1993). Consequently, the importance of response force as a dependent measure lies not only in the confounding potential of response force in accurate interpretation of RT data (Carlton et al., 1987; Delabarre, Logan, \& Reed, 1897; Ulrich \& Wing, 1991; Woodworth, 1938), but also in the potential of response force to shed light on stimulusresponse conductance processes (Giray \& Ulrich, 1993; Jaśkowski \& Włodarczyk, 2006; Mattes, Ulrich, \& Miller, 2002; Schröter, 2006; Stahl \& Rammsayer, 2004; Ulrich, Rinkenauer, \& Miller, 1998; Ulrich \& Wing, 1991). For instance, RT is known to decrease with increased stimulus intensity, and it is well established that stimulus intensity influences the speed of sensory and perceptual processes (for a review, see Miller, Ulrich, \& Rinkenauer, 1999). Yet RT studies that have also incorporated measurement of response force suggest that such stimulus intensity effects cannot be accounted for entirely within the sensory and perceptual systems. Specifically, these studies have also shown response force to vary systematically with changes in stimulus intensity, which suggests that stimulus intensity can affect postperceptual processes as well (Angel, 1973; Jaśkowski \& Włodarczyk, 2006; Miller, Franz, \& Ulrich, 1999).

However, although there has been much discussion of factors involved in the accurate measurement and recording of RTs (Luce, 1986; Plant, Hammond, \& Whitehouse, 2003; Voss, Leonhart, \& Stahl, 2007; Welford, 1980), key issues surrounding the regular, accurate measurement of response force have been far less completely studied. Moreover, there are currently no suitable, commercially available, off-the-shelf response keys that allow for accurate measurement of the force of responses to stimuli. The purpose of the present article, therefore, is to underscore the critical potential offered by modern force transducers, discuss issues surrounding the design of response keys, and present a method by which both response force and RT can be measured regularly and unobtrusively in laboratory-based RT research. To place this technique in perspective, it is necessary to first review the equipment, techniques, and design of response-force keys used previously to measure the force of responses to stimuli.

\section{Techniques for Measuring Response Force}

One of the most popular methods of measuring response force is with electrical resistance strain gauges (Angel, 1973; Freund \& Büdingen, 1978; Giray \& Ulrich, 1993; Ivry, 1986; Kantowitz, 1973; Keele et al., 1987; Klemmer, 1957; Mattes, Ulrich, \& Miller, 1997; Miller \& Franz, 2005; Mordkoff, Miller, \& Roch, 1996; Schäffer, Giray, \& Ulrich, 1989; Schröter, 2006; Stahl \& Rammsayer, 2004; 
Ulrich \& Mattes, 1996; Ulrich et al., 1998; van Boxtel \& Brunia, 1994; van Boxtel et al., 1993; Wild-Wall, Sangals, Sommer, \& Leuthold, 2003). A strain gauge's electrical resistance varies in proportion to the amount of stress it is subjected to, so when bonded to suitably elastic material, it provides an effective means of measuring the force of responses to stimuli.

Strain gauges have been incorporated into a wide range of response devices. For instance, Angel (1973) describes a response device into which participants were required to insert their thumbs, into a padded metal ring connected to a stiff beam on which strain gauges were mounted. Others (Haagh et al., 1987; Kantowitz, 1973; van Boxtel \& Brunia, 1994; van Boxtel et al., 1993; Wild-Wall et al., 2003) describe a response procedure in which participants were required to hold a strain gauge force transducer between the index finger and thumb. Participants responded to stimuli by changing the force of their finger grip. Still others (Giray \& Ulrich, 1993; Mattes et al., 1997; Miller \& Franz, 2005; Mordkoff et al., 1996; Schäffer et al., 1989; Schröter, 2006; Stahl \& Rammsayer, 2004; Ulrich \& Mattes, 1996; Ulrich et al., 1998) describe a method whereby participants were required to press the free end of a metal bar onto which strain gauges were bonded.

An alternative method of measuring response force is with commercially available "load cells" (van den Wildenberg, van Boxtel, \& van der Molen, 2003), which may contain strain gauges or similar technology but with this advantage over bonding strain gauges to metal bars: The shape and deflective properties of the casing that houses the force sensors are manufactured to precise standards. Most notably, some are cylindrically "pancake"-shaped, with a small protruding knob. Such load cells have been placed directly in front of participants for use by fingerpressing on the protruding knob of the load cell (van den Wildenberg et al., 2003).

In practice, all such devices convert the force of responses to a change in electrical resistance by deflection. The more flexible the material onto which the strain gauges are bonded, the longer it takes for the device to return to its resting state, and the less sensitive the device is to dynamic changes in force. Consequently, forces of $10-20 \mathrm{~N}$ are typically required to displace such devices by just a few millimeters (Franz \& Miller, 2002; Giray \& Ulrich, 1993; Schäffer et al., 1989; Stahl \& Rammsayer, 2004) and forces of up to $15 \mathrm{~N}$ (Giray \& Ulrich, 1993) have been reported to arise in responses to stimuli.

\section{Provision of Feedback}

Generally speaking, the classic response in RT experiments is given by fingerpressing a response key of the type found commonly on computer keyboards, computer mice, or commercially available buttonboxes (Crosbie, 1990; Plant et al., 2003; Voss et al., 2007; Welford, 1980). On the basis of recommendations made by the American National Standards Institute (1988), the force required to activate a standard computer keyboard or mouse key should be no more than $1.5 \mathrm{~N}$, and should be accompanied by tactile or auditory feedback or both. On these grounds, there is ample evidence to suggest (Gerard, Armstrong, Rempel, \& Woolley, 2002; Rempel et al., 1997) that the design of modern computer keys serves to constrain, but not control, the force used to respond to stimuli.

Underlying interpretations of response force operate on different assumptions from those generally applied to RT and accuracy, which are generally assumed, on the basis of either implicit or explicit instructions, to be generated under conditions where participants are trying to minimize their RTs and maximize their accuracy. In studies of response force, participants are rarely, if ever, instructed to maximize (or minimize) the force of their responses to stimuli (but see Carlton \& Newell, 1987). Of concern, therefore, is that, absent instruction, the precise force dynamics of keypress responses to stimuli are left implicitly to the discretion of each participant.

In apparent recognition of this concern, Jaśkowski and colleagues (Jaśkowski \& Verleger, 1993; Jaśkowski, Verleger, \& Wascher, 1994; see also Klemmer, 1957) provided participants with feedback by way of an auditory signal generated by the computer's loudspeaker as soon as the force applied to the key reached $2.0 \mathrm{~N}$. Auditory or tactile feedback upon key actuation can be thought of as a system that informs participants that they have reached a desired goal. In short, it provides a response force criterion that, in line with interpretation of RTs (Pachella, 1974), promises to make the additional dependent measure of response force more relevant to substantive issues in RT research.

The method presented here brings with it the benefit of close resemblance to the type of response keys used in RT research. The response key described not only looks like a standard response key, but by incorporating a sensitive microswitch, it provides instantaneous feedback to participants by way of tactile feedback, and emits an audible click when the switch closes.

\section{EXPERIMENT}

Response force was measured by way of four B201-L FlexiForce load sensors, which are specified as having a response time of less than $5 \mu$ s to input force (Tekscan Inc., South Boston). FlexiForce sensors are based on piezoelectric technology that is very hard and deflects very little (i.e., $<0.001 \mathrm{~mm}$ ) when pressed. On the basis of their solidity, force sensors comprising piezoelectric crystals enable a high-frequency response and so are considered particularly well suited to measurement of dynamic force (National Physical Laboratory, Institute of Measurement and Control, 1998).

In the present case, four FlexiForce sensors were bonded to the base of a standard duroplast electrical potting box (Model A80 70 200; OKW Gehäusesysteme GmbH, Buchen, Germany), one in each corner. The beveled edges of the potting box lid were removed so that the lid fit squarely but loosely within the potting box, with a microswitch in the center of the lid. Four 6-mm cap nuts were bonded to the underside of the lid to exert a limited area of pressure on each sensor. A standard household doorbell (No. D824S3A; Friedland, Novar ED\&S Ltd, Basildon, 
A

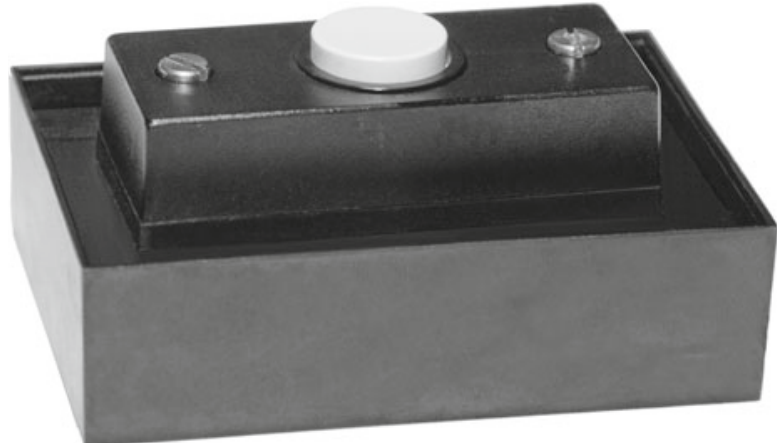

B

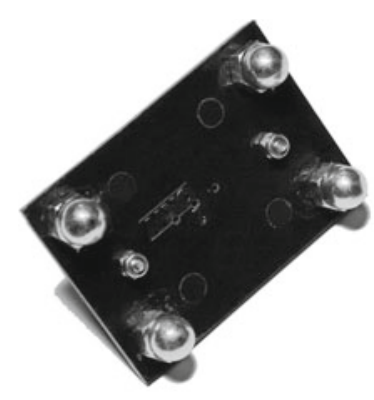

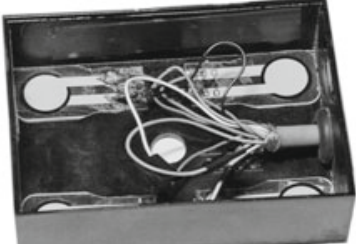

Figure 1. (A) Finalized response key as viewed from the side. (B) Response key showing the underside of the lid and internal components.

U.K.) was used as the response button, with its own internal switch mechanism removed. Then it was positioned centrally, and secured firmly, on the lid of the electrical potting box, so that the pushbutton rested squarely on the microswitch. The microswitch was connected to an ActiveWire USB card (ActiveWire Inc., Campbell, CA) using two of the wires within a standard 12-wire sensor cable. The remaining wires were used to connect the force sensors to a simple electronic drive circuit constructed to amplify the signal in proportion to the pressure applied to each sensor. Photographs of the internal components and final response key, as used by participants, are shown in Figure 1.

The amplification circuit consisted of a terminal panel, two Dual 12-V Power Supply Mini Boards (Futurlec, New York) and, separately for each sensor, two 1-M $\Omega$ trimmers (67W, BI Technologies, Fullerton, CA) and one OP amplifier (OP275), together with a number of short wires to connect the electronic components. The wiring diagram for the amplifier is shown in Figure 2. Amplification of the circuit is given by $V_{\text {out }}=-V_{\text {in }}\left[R_{\mathrm{F} 2} /\left(R_{\mathrm{s}}+R_{\mathrm{F} 1}\right)\right]$. Analog-to-digital conversion was achieved using a National Instruments data acquisition device (NI PCI-6221; National Instruments Corporation, Austin, TX).

All equipment was controlled by way of a standard desktop computer (Dell Precision PWS370, Dell Inc., Round Rock, TX) running MATLAB along with a Data Acquisition Toolbox (The MathWorks, Inc., Natick, MA) ${ }^{2}$ and Psychophysics Toolbox extensions (Brainard, 1997; Pelli, 1997). Timing tests of the experimental setup, conducted with a Black Box Toolkit (Plant, Hammond, \& Whitehouse, 2002) verified the consistency of the timings requested by the experiment script. Specifically, the Black Box Toolkit was used to simulate a response (i.e., switch closure) precisely $300 \mathrm{msec}$ after physical stimulus onset, which, over 100 trials, revealed a constant delay of $7 \mathrm{msec}$ but variance of just $0.6 \mathrm{msec}$ in recorded RTs.

Calibration. The response-force key was calibrated by placing a series of known weights on the key and recording the value returned by the computer. Figure 3 shows

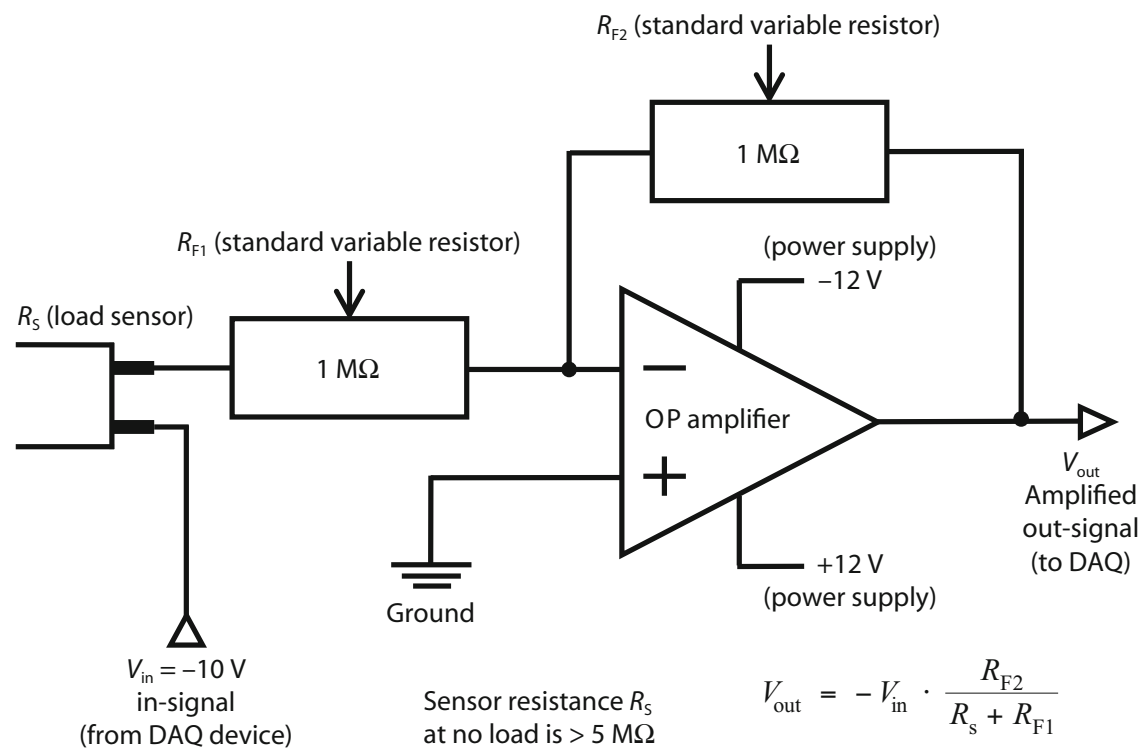

Figure 2. Amplification circuit used to convert resistance to a meaningful force unit. 


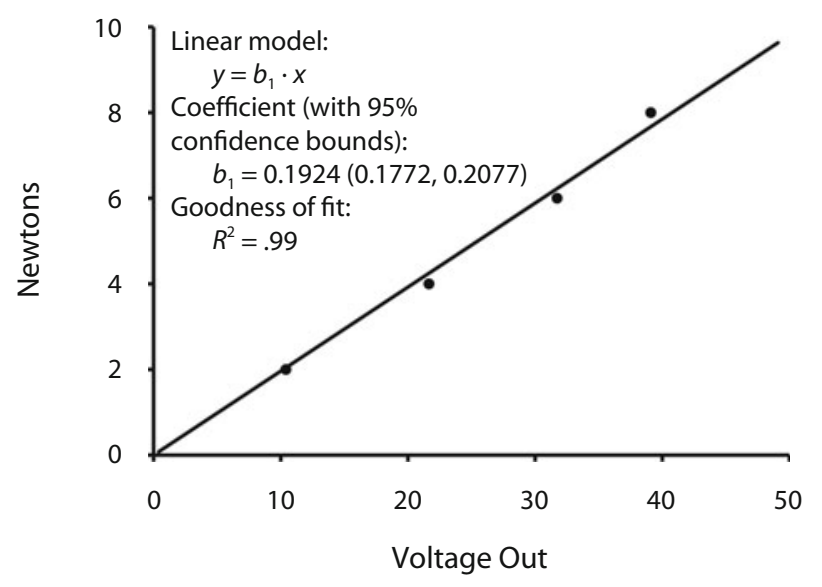

Figure 3. Linear least mean squares fit to the summed voltage output obtained with known weights resting on the response button.

the best-fitting linear regression line, which accounted for over $99 \%$ of the variance. The calibration data obtained in our laboratory closely matched the distribution of factory calibration data described by the manufacturers of the force sensors (i.e., Tekscan, Inc.), using their recommended amplification circuit. ${ }^{3}$

\section{Method}

We decided to conduct a simple experiment using the responseforce key described to examine the effectiveness of the device. In this experiment, three levels of stimulus brightness were combined factorially with three levels of stimulus size to create nine different stimuli of increasing brightness and size. In his pioneering experiment, Angel (1973) found a decrease in RT and an increase in response force with increased stimulus brightness. More recently, however, Jaśkowski and Włodarczyk (2006) found this response force relation to hold for large, but not for small, visual stimuli. On this basis, they suggest that response force intensity relations are related to the arousing properties of the stimuli, since large visual stimuli are assumed to be more arousing than small visual stimuli.

Participants. Thirty participants from Stockholm University, 21 women and 9 men between the ages of 19 and $44(M=27.5)$, took part in the experiment to fulfill a partial course requirement. All participants reported normal or corrected-to-normal vision.

Visual conditions. Visual stimuli were presented on a 21-in. (40.5-cm $\times 30.5-\mathrm{cm}$ viewable area) gamma-corrected ViewSonic G220 $f$ video monitor (ViewSonic Corporation, Walnut, CA), with a pixel resolution of $1,024 \times 768$, at a $100-\mathrm{Hz}$ refresh rate. Stimulus presentations and timing were controlled with a Cambridge Research Systems (Rochester, Kent, U.K.) Bits ++ video processor. Luminance was measured using a ColorCal optical photometer. A chinrest was fixed at a distance of $57 \mathrm{~cm}$ from the screen of the video monitor to ensure a constant viewing distance. The desktop computer used to control the experiment was placed outside and adjacent to the testing room. All other peripheral equipment was concealed behind black board, ensuring that only the screen of the video monitor was visible to participants.

Stimuli. The visual stimuli were centrally presented rectangular patches. Each rectangular patch was presented at one of three brightness levels and at one of three different sizes. The luminance of the rectangular patches was either $0.5,4$, or $30 \mathrm{~cd} / \mathrm{m}^{2}$, and their size was either $3^{\circ} \times 2.8^{\circ}$ (small), $6^{\circ} \times 5.6^{\circ}$ (medium), or $18^{\circ} \times 16.8^{\circ}$ (large) of visual angle. These three different brightness levels and three different stimulus sizes were combined factorially to create nine different stimuli.

Design. Participants were tested individually in a quiet, darkened testing room in one 40 -min session of 504 trials. Stimuli were shown in pseudorandomly constructed cycles of 18 trials, containing two instances of all possible factorial combinations of brightness and size. At the end of each block of 36 trials, participants were required to make an additional buttonpress to initiate the next block of trials. The first block of 36 trials served as practice and was eliminated from data analysis. To minimize stimulus anticipation, the intertrial interval between stimulus onsets was random, with a mean duration of $3 \mathrm{sec}$, comprising the sum of a constant $2 \mathrm{sec}$ and an exponentially distributed random variable with a mean of $1 \mathrm{sec}$.

Procedure. At the start of the session, each participant was presented with the written instructions on the monitor to respond as quickly and as accurately as possible, on detection of a visual stimulus, using the right index finger. These instructions were read to participants and the importance of responding as quickly and as accurately as possible was stressed. RT was measured from stimulus onset to the closure of the microswitch, via the ActiveWire USB card, and to a minimum force criterion of $1.5 \mathrm{~N}$, defined in terms of the mean amplified resistance of the four force sensors; the resistance of the force sensors was sampled for $1,500 \mathrm{msec}$ from stimulus onset at a sampling rate of $1000 \mathrm{~Hz}$. Immediately following a response of less than $100 \mathrm{msec}$ or longer than $1,000 \mathrm{msec}$, the message "Anticipation" or "Miss" was presented on the computer screen and a further buttonpress was required to continue.

\section{Results}

RTs and peak forces - defined as the maximum exerted force on each trial - were averaged over trials for each condition and for each participant separately. Figure 4 provides a graphical representation of these data. All RTs reported are based on the time from stimulus onset to a minimum force criterion of $1.5 \mathrm{~N}$ as measured with the force sensors, but the same pattern of RTs obtained when measured from stimulus onset to the closure of the microswitch. In analyses of the data, all responses under $100 \mathrm{msec}$ were defined as premature and discarded; only $1.35 \%$ of responses were premature. The differences between percentages of premature responses from one condition to another were very small and statistically insignificant. 

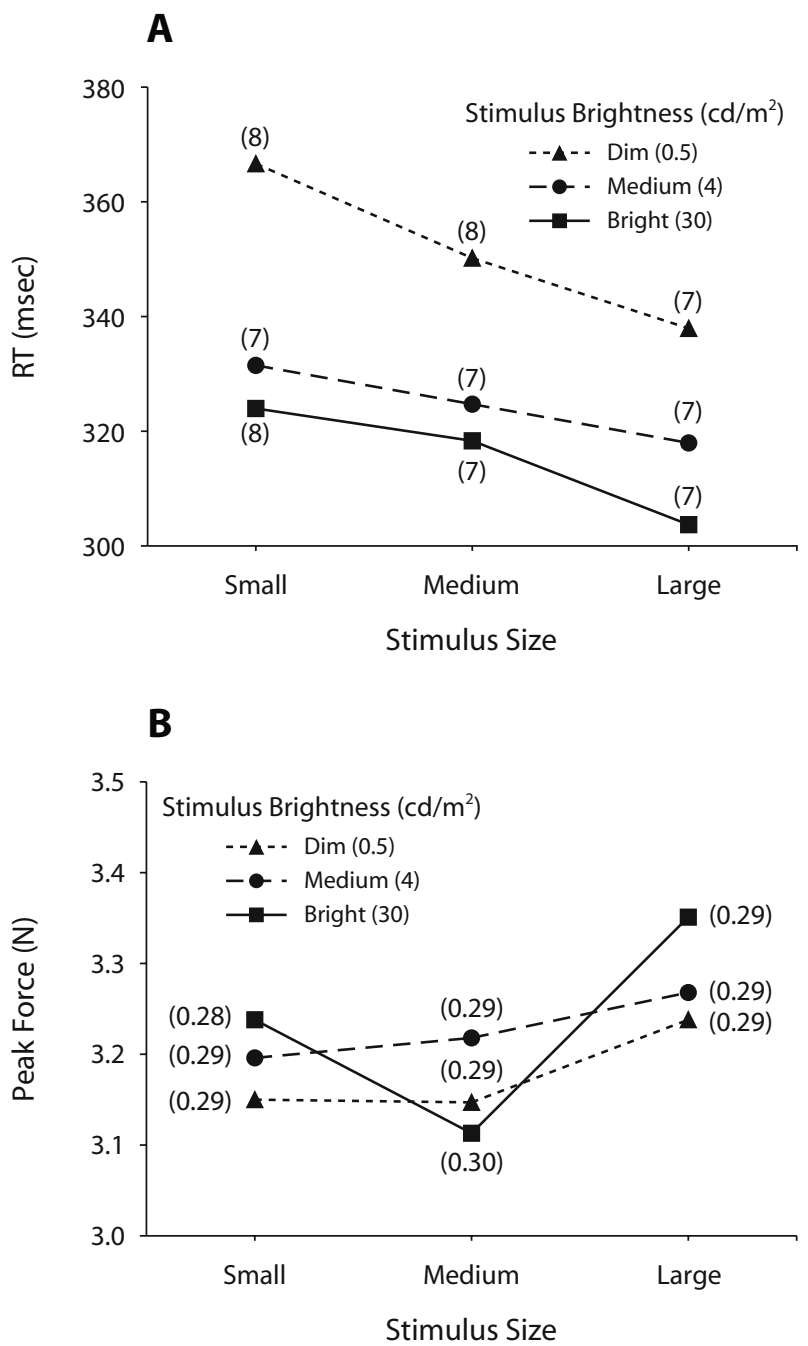

Figure 4. (A) Mean response times. (B) Mean peak forces, as a function of stimulus size and brightness. Standard errors of the means are shown in parentheses.

Misses were defined as cases in which a stimulus was presented but the participant failed to make a response within 1,000 msec. A repeated measures ANOVA with two within-participants factors (stimulus brightness, stimulus size) revealed a main effect of stimulus brightness $\left[F(2,58)=10.48, p<.001, \eta_{\mathrm{p}}^{2}=.26\right]$. Tukey's HSD tests showed that participants missed more dim stimuli than they did medium bright and bright stimuli $(0.61 \%$ vs. $0.35 \%$ and $0.26 \%$; both $p \mathrm{~s}<.01)$. Overall, however, there were only $1.22 \%$ misses, and these data were removed from all other analyses.

The remaining data were submitted to two separate repeated measures ANOVAs - one for the RT data and one for the peak force data. Each ANOVA contained two within-participants factors (stimulus brightness and stimulus size). A Greenhouse-Geisser correction (Greenhouse $\&$ Geisser, 1959) was used to provide a more conservative analysis, where necessary, to compensate for violations of the sphericity assumption.
RT. Analysis of the RT data revealed statistically significant main effects of stimulus brightness $[F(2,58)=$ $\left.145.53, p<.001, \eta_{\mathrm{p}}^{2}=.83\right]$ and stimulus size $[F(2,58)=$ $52.91, p<.001, \eta_{\mathrm{p}}^{2}=.65$ ], along with a statistically reliable interaction between stimulus brightness and stimulus size $\left[F(4,116)=3.31, p=.01, \eta_{\mathrm{p}}^{2}=.10\right]$.

Simple main effects analyses were carried out in order to establish the reasons for the statistically reliable stimulus brightness $\times$ stimulus size interaction. These analyses showed statistically significant effects of stimulus brightness for each of the three levels of stimulus size: small $\left[F(2,58)=63.82, p<.001, \eta_{\mathrm{p}}^{2}=.69\right]$, medium $[F(2,58)=$ $\left.62.01, p<.001, \eta_{\mathrm{p}}^{2}=.68\right]$, and large $[F(2,58)=52.72$, $\left.p<.001, \eta_{\mathrm{p}}^{2}=.83\right]$. In addition, these analyses revealed statistically significant effects of stimuli size for each of the three levels of stimulus brightness: $\operatorname{dim}[F(2,58)=$ $\left.33.49, p<.001, \eta_{\mathrm{p}}^{2}=.54\right]$, medium $[F(2,58)=9.41$, $\left.p<.001, \eta_{\mathrm{p}}^{2}=.25\right]$, and bright $[F(2,58)=17.85, p<$ $\left..001, \eta_{\mathrm{p}}^{2}=.38\right]$. As Figure 4A shows, RT decreased monotonically with increased stimulus size and with increased brightness, but more rapidly with increased brightness than with increased stimulus size.

Peak force. Analysis of peak forces revealed a statistically significantly main effect of stimulus size $[F(2,58)=$ $8.48, p=.001, \eta_{\mathrm{p}}^{2}=.23$ ] and a statistically significant interaction between stimulus brightness and stimulus size $\left[F(4,116)=2.57, p=.04, \eta_{\mathrm{p}}^{2}=.08\right]$. The main effect of stimulus brightness was not statistically reliable $[F(2,58)=1.14, p=.33]$.

Simple main effects analyses revealed a statistically significant effect of stimulus size for the brightest stimuli $\left[F(2,58)=11.77, p<.001, \eta_{\mathrm{p}}^{2}=.29\right]$. Tukey's HSD tests showed the peak forces of responses to the medium sized stimuli to be lower than those to the smallest and largest sized stimuli (3.11 vs. 3.24 and $3.35 \mathrm{~N}$, respectively; both $p \mathrm{~s}<.01)$. None of the other tests produced a statistically significant result.

\section{Discussion}

The response key described allows the benefits of measuring response force to be extended by provision of auditory and tactile feedback about response key activation. The use of a response-force key that operates like a standard computer key is a simple but effective method of providing a criterion response-force level that promises to make interpretation of response force more widely available for any RT task in which a classic keypress response is required.

The force sensors used in the present study cost about the same as standard strain gauges, but do not require bonding to suitably elastic material, and cost considerably less than load cells, or other custom-built force sensing devices. In the main, the other equipment used to construct the response key and amplification circuit can be purchased inexpensively from local suppliers. In the present case, we chose to record RTs via the computer's USB port using an ActiveWire card, although RTs could be recorded equally accurately by way of a computer's parallel port (Voss et al., 2007). Likewise, various analogto-digital data acquisition hardware devices can be pur- 
chased economically from a wide variety of sources. Many psychological experimenting systems (e.g., Presentation, E-Prime) provide software tools for interacting with common data acquisition devices; also, suitable experimental software may be written in-house. The point is that by embedding force sensors into standard response boxes and response keys, response force in RT research may be measured accurately, unobtrusively, and regularly.

The benefits of this approach may be applied to the development of methodologies involving RT and responseforce measures in the investigation of substantive psychophysical issues. For instance, by incorporating sensitive force sensors into standard response keys, the regular and unobtrusive measurement of response force allows for the everyday experimental examination and, where necessary, statistical control of motor-related factors in subsequent interpretation of RTs.

In line with previous studies (Angel, 1973; Jaśkowski \& Włodarczyk, 2006; Kohfeld, 1971), the findings of the present experiment show a monotonic decrease in RT with increased stimulus size and with increased stimulus brightness. Moreover, the data show a trend for the peak force of responses to increase with increased stimulus size and with increased stimulus brightness. These findings conform to research that has shown response force to increase monotonically with increased physical intensity of visual stimuli (Angel, 1973; Mattes \& Ulrich, 1997; Ulrich et al., 1998). However, this is not always the case (Jaśkowski \& Włodarczyk, 2006; Miller, Ulrich, \& Pfaff, 1991), and in the present experiment no statistically reliable monotonic relation obtained between the brightness or size of the stimuli and peak response force. The point of departure is that the present findings show a decrease in peak response forces to the medium, compared with the smaller and larger sized stimuli at the brightest stimulus level.

Taken together, the different patterns of RT and response-force data obtained support the view that changes in visual intensity primarily influence the duration of perceptual, not motor-related, processes (Jaśkowski \& Włodarczyk, 2006; Miller et al., 1999). The generally low levels of peak force used by participants in the present study, compared with previous studies (e.g., Jaśkowski \& Włodarczyk, 2006; Mattes \& Ulrich, 1997; Ulrich et al., 1998), and the skewed V-shaped pattern of peak forces at the brightest stimulus level suggest that precise patterns of peak response-force data may, at least in part, depend on the operational demands of the response device and on perceived experimental demands. For instance, one possibility is that participants sought to anchor the force of their responses to a reference level based on the auditory and tactile feedback provided on switch closure and on the basis of incoming stimulus information (after Helson, 1964), resulting in lower peak forces to the medium sized stimuli, rather than to the smaller and larger sized stimuli at the brightest stimulus level. However, this is not to say that response feedback is a confounding factor in the incorporation of response-force measures in RT research, since the response keys used in most RT studies provide auditory and tactile feedback on switch closure.
In support of the assumption that the temporal and dynamic aspects of responses to stimuli are at least partly independent of each other, researchers (Giray \& Ulrich, 1993; Mordkoff et al., 1996; Stahl \& Rammsayer, 2005) have largely failed to detect a correlational relationship between RT and the peak force of response to stimuli. Moreover, there is ample evidence to suggest that participants can systematically and strategically control the force of their responses tailored to the external situation (for a review, see Ulrich \& Wing, 1991). Indeed, researchers have exploited participants' ability to control precisely the force dynamics of their responses by defining response force as an independent variable (Carlton et al., 1987; Carlton \& Newell, 1987; Mattes, Leuthold, \& Ulrich, 2002; Schröter, 2006). In these studies, response forces have been controlled strategically by way of pretrial instructions and posttrial feedback about the desired force parameters of each response. They indicate that changes in the kinetic parameters of responses can result in considerable shifts in measured RTs. Consequently, although there is evidence to suggest that the force dynamics of responses to stimuli can vary independently of RT, there is also evidence that strategic changes in response force to different stimuli can result in significant shifts in RT data.

The response key described provides the means by which to investigate further the confounding potential of strategic shifts in response force in studies of RT. In the present case, a sensitive microswitch was built into the response device to emulate the operation of a standard computer key, as used typically in RT research. The advantage of this approach is that, in line with computer keyboard and mouse keys, the response key described in the present article provides both tactile and auditory feedback on key activation. However, by way of a solid key that does not provide tactile feedback, and by systematic variation of the minimal levels of force required to actuate auditory feedback, more precise details may be obtained about the influence of strategic changes in response forces on patterns of obtained RT data. In particular, by systematic variation of the force required to actuate auditory feedback, strategic variation in the force of responses to stimuli may be invoked subtly without extending the experimental procedure and without the need to inform participants explicitly that the force of their responses is being measured.

Usually, computer keys are pressed with suitable force without explicit thought. Although further research is required to understand the extent to which explicit information about response force influences the generation of responses to stimuli, the method presented here provides the means to examine this issue further. For instance, by using a key that resembles a standard response key, and by systematic variation of the information given to participants, important clues may be obtained concerning the influence of different response-force instructions - and even awareness that response force is being measuredon participants' response strategies in RT experiments.

Much more needs to be known about the strategies adopted by participants in the generation of responses to 
stimuli before confidence can be high about incorporating response-force measures in substantive RT controversies. Of considerable importance to the development of methodologies involving response force is the careful and explicit examination of issues underlying the accurate measurement of response force as a dependent measure in itself. Until then, great care is required to limit the possibility of serious error in the interpretation of response force in RT research.

\section{AUTHOR NOTE}

The research reported here was supported by a grant from the Swedish Research Council awarded to G.R.P. Correspondence regarding this work may be addressed to G. R. Patching, Department of Psychology, Stockholm University, Stockholm, Sweden (e-mail: grp@psychology .su.se).

\section{REFERENCES}

American National Standards Institute (1988). ANSI/HFES 1001988: American National Standard for Human Factors Engineering of Visual Display Terminal Workstations. Santa Monica, CA: Human Factors and Ergonomics Society, Inc.

ANGEL, A. (1973). Input-output relations in simple reaction time experiments. Quarterly Journal of Experimental Psychology, 25, 193-200.

Brainard, D. H. (1997). The Psychophysics Toolbox. Spatial Vision, 10, 433-436. doi:10.1163/156856897X00357

Carlton, L. G., Carlton, M. J., \& Newell, K. M. (1987). Reaction time and response dynamics. Quarterly Journal of Experimental Psychology, 39A, 337-360.

Carlton, L. G., \& Newell, K. M. (1987). Response production factors and reaction time. Bulletin of the Psychonomic Society, 25, 373-376.

Crosbie, J. (1990). The Microsoft mouse as a multipurpose response device for the IBM PC/XT/AT. Behavior Research Methods, Instruments, \& Computers, 22, 305-316.

Delabarre, E. B., Logan, R. R., \& Reed, A. Z. (1897). Studies from the Harvard Psychological Laboratory IX: The force and rapidity of reaction movements. Psychological Review, 4, 615-631. doi:10.1037/ h0072712

FranZ, E. A., \& Miller, J. (2002). Effects of response readiness and reaction time and force output in people with Parkinson's disease. Brain, 125, 1733-1750. doi:10.1093/brain/awf192

Freund, H.-J., \& BÜDINGEN, H. J. (1978). The relationship between speed and amplitude of the fastest voluntary contractions of human arm muscles. Experimental Brain Research, 31, 1-12.

Gerard, M. J., Armstrong, T. J., Rempel, D. A., \& Woolley, C. (2002). Short term and long term effects of enhanced auditory feedback on typing force, EMG, and comfort while typing. Applied Ergonomics, 33, 129-138. doi:10.1016/S0003-6870(01)00062-X

Giray, M., \& Ulrich, R. (1993). Motor coactivation revealed by response force in divided and focused attention. Journal of Experimental Psychology: Human Perception \& Performance, 6, 1278-1291. doi:10.1037/0096-1523.19.6.1278

Greenhouse, S. W., \& Geisser, S. (1959). On methods in the analysis of profile data. Psychometrika, 24, 95-112. doi:10.1007/BF02289823

Haagh, S. A. V. M., Spijkers, W. A. C., van den Boogaart, B., \& VAN BoXTel, A. (1987). Fractioned reaction time as a function of response force. Acta Psychologica, 66, 21-35. doi:10.1016/0001 -6918(87)90016-3

Helson, H. (1964). Adaptation-level theory. New York: Harper \& Row.

IVRY, R. B. (1986). Force and timing components of the motor program. Journal of Motor Behavior, 18, 449-474.

JaŚKOWSKI, P., \& VerLeger, R. (1993). A clock paradigm to study the relationship between expectancy and response force. Perceptual \& Motor Skills, 77, 163-174.

JaŚKowski, P., Verleger, R., \& Wascher, E. (1994). Response force and reaction time in a simple reaction task under time pressure. Zeitschrift für Psychologie, 202, 405-413.
JAŚKowski, P., \& WŁodarczYK, D. (2006). Task modulation of the effects of brightness on reaction time and response force. International Journal of Psychophysiology, 61, 98-112. doi:10.1016/j ijpsycho.2005.07.010

KANTOWITZ, B. H. (1973). Response force as an indicant of conflict in double stimulation. Journal of Experimental Psychology, 100, 302309. doi: $10.1037 / \mathrm{h} 0035780$

KeEle, S. W., Ivry, R. I., \& PoKorny, R. A. (1987). Force control and its relation to timing. Journal of Motor Behavior, 19, 96-114.

KLEMMER, E. T. (1957). Rate of force application in a simple reaction time test. Journal of Applied Psychology, 41, 329-332. doi:10.1037/ h0045067

KoHFELD, D. L. (1971). Simple reaction time as a function of stimulus intensity in decibels of light and sound. Journal of Experimental Psychology, 88, 251-257. doi:10.1037/h0030891

LucE, D. R. (1986). Response times. New York: Oxford University Press.

Mattes, S., Leuthold, H., \& Ulrich, R. (2002). Stimulusresponse compatibility in intensity-force relations. Quarterly Journal of Experimental Psychology, 55A, 1175-1191. doi:10.1080/ 02724980244000152

Mattes, S., \& UlRich, R. (1997). Response force is sensitive to the temporal uncertainty of response stimuli. Perception \& Psychophysics, 59, 1089-1097.

Mattes, S., Ulrich, R., \& Miller, J. (1997). Effects of response probability on response force in simple RT. Quarterly Journal of Experimental Psychology, 50A, 405-420. doi:10.1080/027249897392152

Mattes, S., Ulrich, R., \& Miller, J. (2002). Response force in RT tasks: Isolating effects of stimulus probability and response probability. Visual Cognition, 9, 477-501. doi:10.1080/13506280143 000548

Miller, J. O., \& Franz, E. A. (2005). Dissociation of bimanual responses with the Simon effect: On the nonunitization of bimanual responses. Journal of Motor Behavior, 37, 146-156. doi:10.3200/ JMBR.37.2.146-156

Miller, J. [O.], Franz, V., \& Ulrich, R. (1999). Effects of auditory stimulus intensity on response force in simple, go/no-go, and choice RT tasks. Perception \& Psychophysics, 61, 107-119.

Miller, J. [O.], Ulrich, R., \& PfafF, K. (1991). Visual stimulus intensity does not influence response force. Paper presented at the 32nd Annual Meeting of the Psychonomic Society, San Francisco, CA.

Miller, J. [O.], Ulrich, R., \& Rinkenauer, G. (1999). Effects of stimulus intensity on the lateralized readiness potential. Journal of Experimental Psychology: Human Perception \& Performance, 25, 1454-1471. doi:10.1037/0096-1523.25.5.1454

Mordkoff, J. T., Miller, J., \& Roch, A. C. (1996). Absence of coactivation in the motor component: Evidence from psychophysical measures of target detection. Journal of Experimental Psychology: Human Perception \& Performance, 22, 25-41. doi:10.1037/0096 $-1523.22 .1 .25$

National Physical Laboratory (1998). Guide to the measurement of force. London: Institute of Measurement and Control.

Pachella, R. G. (1974). The interpretation of reaction time in information processing research. In B. Kantowitz (Ed.), Human information processing: Tutorials in performance and cognition (pp. 41-82). New York: Halstead Press.

Pelli, D. G. (1997). The VideoToolbox software for visual psychophysics: Transforming numbers into movies. Spatial Vision, 10, 437442. doi: $10.1163 / 156856897 \mathrm{X} 00366$

Plant, R. R., Hammond, N., \& Whitehouse, T. (2002). Toward an Experimental Timing Standards Lab: Benchmarking precision in the real world. Behavior Research Methods, Instruments, \& Computers, 34, 218-226.

Plant, R. R., Hammond, N., \& Whitehouse, T. (2003). How choice of mouse may affect response timing in psychological studies. Behavior Research Methods, Instruments, \& Computers, 35, 276-284.

Rempel, D., Serina, E., Klinenberg, E., Martin, B. J., Armstrong, T. J., FoulKe, J. A., \& Natarajan, S. (1997). The effect of keyboard keyswitch make force on applied force and finger flexor muscle activity. Ergonomics, 40, 800-808. doi:10.1080/001401397187793

SCHäFFER, R., Giray, M., \& UlRich, R. (1989). A simple reaction-key 
for force measurement. Unpublished manuscript, Eberhard-KarlsUniversität Tübingen.

SCHRÖter, H. (2006). Programming of time-to-peak force of brief isometric force pulses: Effects on reaction time. Quarterly Journal of Experimental Psychology, 59, 1277-1305.

Sommer, W., Leuthold, H., \& UlRich, R. (1994). The lateralized readiness potential preceding brief isometric force pulses of different peak force and rate of force production. Psychophysiology, 31, 503-512. doi:10.1111/j.1469-8986.1994.tb01054.x

Stahl, J., \& RAMmsayeR, T. [H.] (2004). Differences in the transmission of sensory input into motor output between introverts and extraverts: Behavioral and psychophysiological analyses. Brain \& Cognition, 56, 293-303. doi:10.1016/j.bandc.2004.07.004

Stahl, J., \& RAmmsayer, T. H. (2005). Accessory stimulation in the time course of visuomotor information processing: Stimulus intensity effects on reaction time and response force. Acta Psychologica, 120, 1-18. doi:10.1016/j.actpsy.2005.02.003

Ulrich, R., \& Mattes, S. (1996). Does immediate arousal enhance response force in simple reaction time? Quarterly Journal of Experimental Psychology, 49A, 972-990. doi:10.1080/027249896392397

Ulrich, R., RinkENAUER, G., \& Miller, J. (1998). Effects of stimulus duration and intensity on simple reaction time and response force. Journal of Experimental Psychology: Human Perception \& Performance, 24, 915-928. doi:10.1037/0096-1523.24.3.915

UlRICH, R., \& WING, A. M. (1991). A recruitment theory of force-time relations in the production of brief force pulses: The parallel force unit model. Psychological Review, 98, 268-294. doi:10.1037/0033 $-295 X .98 .2 .268$

van Boxtel, G. J. M., \& Brunia, C. H. M. (1994). Motor and nonmotor components of the contingent negative variation. International Journal of Psychophysiology, 17, 269-279. doi:10.1016/0167 -8760(94)90069-8

van Boxtel, G. J. [M.], van den BoogaArt, B., \& Brunia, C. H. (1993). The contingent negative variation in a choice reaction time task. Journal of Psychophysiology, 7, 11-23.
VAN Den Wildenberg, W. P. M., VAn Boxtel, G. J. M., \& VAN DeR Molen, M. W. (2003). The duration of response inhibition in the stopsignal paradigm varies with response force. Acta Psychologica, 114, 115-129. doi:10.1016/S0001-6918(03)00062-3

Voss, A., Leonhart, R., \& Stahl, C. (2007). How to make your own response boxes: A step-by-step guide for the construction of reliable and inexpensive parallel-port response pads from computer mice. Behavior Research Methods, 39, 797-801.

Welford, A. T. (ED.) (1980). Reaction times. New York: Academic Press.

Wild-Wall, N., Sangals, J., Sommer, W., \& Leuthold, H. (2003). Are fingers special? Evidence about movement preparation from eventrelated potentials. Psychophysiology, 40, 7-16. doi:10.1111/1469 $-8986.00002$

WoODWORTH, R. S. (1938). Experimental psychology. New York: Henry Holt.

\section{NOTES}

1. The standard unit of force is the Newton $(\mathrm{N})$, defined as the unit of force that would give to a mass of $1 \mathrm{~kg}$ an acceleration of $1 \mathrm{~m} / \mathrm{sec}^{2}$. As such, $1 \mathrm{~kg}$ force is equivalent to $9.81 \mathrm{~N}$.

2. The Data Acquisition Toolbox is a set of software tools available from The MathWorks, Inc. that can be used within MATLAB for recording analog input and triggering analog output from a variety of PCcompatible data acquisition hardware devices.

3. The amplification circuit recommended by the manufacturers of the FlexiForce sensors is similar but not identical to the amplification circuit detailed in Figure 2. In the present case, the voltage supply was increased and an additional resistor added to increase sensitivity and decrease static noise.

(Manuscript received February 20, 2009; revision accepted for publication June 16, 2009.) 